\title{
REACTIVE OXYGEN SPECIES IN HUMAN SEMEN IN RELATION TO LEUKOCYTE CONTAMINATION
}

\author{
Ivana Oborna ${ }^{a *}$, Helena Fingerova ${ }^{\mathrm{a}}$, Jiri Novotny ${ }^{\mathrm{b}}$, Jana Brezinova ${ }^{\mathrm{a}}$, \\ Magda Svobodova ${ }^{\mathrm{a}}$, Nabil Aziz ${ }^{\mathrm{c}}$
}

\author{
a Department of Obstetrics and Gynecology, Faculty of Medicine and Dentistry, Palacky University, Olomouc, Czech Republic \\ b Department of Biology, Faculty of Medicine and Dentistry, Palacky University \\ c Liverpool Women's Hospital, Liverpool, UK \\ e-mail: obornai@fnol.cz
}

Received: August 1, 2008; Accepted: September 11, 2008

Key words: Reactive oxygen species/Polymorphonuclear neutrophils/Human spermatozoa/Male infertility

Aims: Excessive production of reactive oxygen species (ROS) in semen has been linked to male infertility. Main sources of ROS in male genital tract are immature and/or damaged spermatozoa and a subpopulation of leukocytes known as polymorphonuclear neutrophils (PMN).

Methods: Study group included male partners of infertile couples, 67 normospermic males (group B) and 98 males with sperm abnormalities in one or more parameters (group C), 36 fertile volunteers (group A) served as controls. Sperm parameters were determined according to WHO guidelines. The ROS production was measured by chemiluminiscence in sperm suspension in phosphate buffered saline.

Results: All fertile volunteers in the control group had seminal PMN concentrations below $0.5 \times 10^{6} / \mathrm{ml}$. Therefore study subjects, 67 normospermic and 98 men with sperm abnormalities, were further subdivided into two subgroups of PMN concentrations: (1) $<0.5 \times 10^{6} / \mathrm{ml}$ and (2) 0.5 to $1.0 \times 10^{6} / \mathrm{ml}$. The ROS production in individuals varied greatly from $1.0 \times 10^{2}$ to $1.7 \times 10^{7} \mathrm{RLU} / \mathrm{min}$ per $20 \times 10^{6}$ spermatozoa. The ROS production in both subgroups of normospermic men and the subgroup (1) of men with sperm abnormalities was not different from the ROS production in fertile controls. The ROS production in the subgroup (2) with sperm abnormalities was significantly higher than in controls $(\mathrm{P}=0.00004)$.

Conclusions: Our findings suggest that the contribution of PMN to the ROS production in semen is negligible only up to a concentration of $0.5 \times 10^{6} / \mathrm{ml}$. This suggests that the current WHO Guidelines threshold of $1.0 \times 10^{6} \mathrm{PMN}$ per $\mathrm{ml}$ of semen is too high and might be re-evaluated.

\section{INTRODUCTION}

Semen analysis is an essential component of the investigation of male fertility. The extent of examination and the techniques used (manual, semi-automatic or automatic computer-assisted semen analysis) varies. An inherent part of such analyses is the Endtz test which detects a subpopulation of white blood cells (WBC) known as polymorphonuclear neutrophils (PMN) (ref. $\left.{ }^{1}\right)$. According to WHO Guidelines ${ }^{2}$ the cut-off limit for the presence of PMN in human semen is $1.0 \times 10^{6} / \mathrm{ml}$. These WBC, an integral part of defence system against infection, can produce large quantities of reactive oxygen species (ROS) during an oxidative burst ${ }^{3}$. When activated, PMN produce ROS significantly more than other known sources such as immature or morphologically abnormal spermatozoa ${ }^{4}$.

ROS have contrasting roles in male fertility. In physiologically small amounts, ROS are necessary for sperm capacitation, sperm hyperactivation, acrosome reaction and sperm-oocyte fusion ${ }^{5}$. In large amounts, they are toxic to sperm. The lack of cytoplasmic defences renders spermatozoa more susceptible to oxidative stress $^{6,7}$. Moreover, spermatozoa are particularly sensitive to oxidative damage by lipid peroxidation due to the high content of polyunsaturated fatty acids, mainly docosahexaenoic acid ${ }^{8}$ in their membranes. ROS also diminish intracellular ATP, which in turn leads to a reduction in axonemal protein phosphorylation and to sperm immobilization ${ }^{4}$. The latest reports stress the association of excessive ROS generation with DNA strand breaks ${ }^{9,10}$ and chromosome deletions in spermatozoa ${ }^{11}$. These changes may not be detected by routine semen analysis although they can cause reproductive failure.

Under physiological conditions ROS levels in ejaculates is well-controlled by enzymatic and non-enzymatic antioxidant systems in seminal plasma. Pathological conditions, in contrast, can lead to an imbalance between ROS production and the antioxidant defense system and thus create oxidative stress (OS) which is known to have a negative effect on male fertility.

The contribution of leukocytospermia to impairming the fertilizing ability of sperm was first studied in the mid-nineteen eighties ${ }^{12}$, but since then conflicting opinions have been expressed. For instance, Ochsendorf ${ }^{8}$ stated that only very high numbers of leukocytes, at least $>2.0 \times 10^{6} \mathrm{PMN}$ per $\mathrm{ml}$, generate excessive ROS which 
can not be counteracted by the antioxidant capacity of seminal plasma. Moskovtsev ${ }^{13}$ found only weak correlation between WBC concentration in ejaculate and sperm DNA fragmentation index but a significant negative effect of $\mathrm{WBC}$ on the standard semen parametres. In contrast, Sharma et $\mathrm{al}^{14}$ observed that any presence of leukocytes between 0 and $1.0 \times 10^{6} / \mathrm{ml}$ was associated with oxidative stress and they were unable to determine a "safe" minimal leukocyte count. Our study aims to bring more evidence to bear on the relationship between PMN counts in human semen and total ROS production measured in sperm suspensions.

\section{MATERIALS AND METHODS}

\section{The study population}

The study was approved by the Institutional Review Board of Palacky University. All subjects gave their written consent. The study group included male partners of 185 consecutive infertile couples referred to the programme of assisted reproduction at the Department of Obstetrics and Gynaecology, Faculty of Medicine and Dentistry Palacky University in 2006 and 2007. Reference semen samples were collected from 36 fertile volunteers who had fathered a child in the previous 12 months. Serum levels of C-reactive protein (CRP) were determined as a routine marker in all subjects to exclude the presence of an acute inflammation at the time of semen collection.

\section{Semen collection and analysis}

Semen samples were collected by masturbation after a period of 3 to 5 days of sexual abstinence. After liquefaction $\left(37^{\circ} \mathrm{C}, 30\right.$ minutes), smears of neat semen were prepared for sperm morphology assessment (Papanicolaou staining). Semen analysis was performed to measure sperm concentration and percentage of motility using WHO criteria ${ }^{2}$. A sample was classified as normospermic if semen volume was $\geq 2 \mathrm{ml}$, sperm concentration was $\geq$ $20 \times 10^{6}$ per $\mathrm{ml}$, sperm motility was $\geq 50 \%$, normal sperm morphology $\geq 30 \%$ and PMN detected by Endtz test $\leq$ $1 \times 10^{6}$ per $\mathrm{ml}$ of ejaculate. Samples which did not fulfil one or more of these criteria were classified as abnormal.

\section{Determination of PMN leukocyte concentration}

The presence of PMN leukocytes in semen was assessed by myeloperoxidase (Endtz) test ${ }^{1}$. Twenty $\mu 1$ of liquefied semen was mixed with $20 \mu$ phosphate buffered saline (PBS; pH 7.0) and $40 \mu \mathrm{l}$ of benzidine (4,4'-diaminobiphenyl, $13.6 \mathrm{mM}$, Sigma Aldrich). After mixing the sample was left for 5 minutes at room temperature. Peroxidase-positive (brown-stained) leukocytes were counted in a Bürker's chamber (Superior GmBH, Marienfeld, Germany) and concentration per $\mathrm{ml}$ of ejaculate was calculated.

\section{ROS detection by chemiluminescent assay}

Aliquots of liquefied semen were centrifuged at $300 \times \mathrm{g}$ for $7 \mathrm{~min}$. The sperm pellets were washed with PBS and resuspended in $1 \mathrm{ml}$ of PBS and further diluted to a concentration of 20 million spermatozoa per $\mathrm{ml}$. In the case of oligospermia (sperm concentration below $20 \times 10^{6}$ per $\mathrm{ml}$ ) the luminescent signal was appropriately multiplied to correspond to $20 \times 10^{6}$ per ml. ROS production was estimated within $30 \mathrm{~min}$ after liquefaction by chemiluminescence following the addition of $10 \mu \mathrm{l}$ of $5 \mathrm{mM}$ luminol (5-amino-2,3-dihydro-1,4 phthalazinedione, Sigma Aldrich) in dimethyl sulfoxide (DMSO, Sigma Aldrich) to $400 \mu \mathrm{l}$ of sperm suspension. Blank tube containing 400 $\mu \mathrm{l}$ of PBS buffer and $5 \mu \mathrm{l}$ of Luminol was used as assay control. Light emission was measured for $15 \mathrm{~min}$ using a DCR-1 luminometer (Digene Diagnostics, Inc.). The results were expressed as relative light units RLU/20×10 sperm/15 min. The method was described in detail by Novotny et $\mathrm{al}^{15}$.

\section{Statistical analysis}

STATISTICA Cz data analysis software (version 6; StatSoft Inc, 2001) was used for statistical calculations. Summary statistics are presented as mean and standard deviation $( \pm \mathrm{SD})$ for Gaussian distributed variables and medians for non-Gaussian ones. Due to the extremely large range of absolute values of ROS production statistical comparisons of ROS levels among groups was performed after logarithmic transformation of RLU/ min. Kruskal-Wallis ANOVA and non-parametric MannWhitney U test were utilized to compare ROS level between groups. The Student $t$ test was used for comparison of sperm parameters. All hypothesis testing was two-tailed and $p<0.05$ was considered statistically significant.

\section{RESULTS}

Of the 185 consecutive patients referred with their partners for assisted conception 20 (10.8\%) were excluded from further evaluation as their ejaculate did not contain enough sperm (at least $5 \times 10^{6}$ spermatozoa $/ \mathrm{ml}$ ) to allow a reliable ROS measurement. Of the remaining 165 patients 67 (40.6\%) were normospermic (group B) and $98(59.4 \%)$ had abnormalities in one or more sperm parameter (group C). There was no evidence of significant difference in mean age between healthy volunteers (group A), group B patients and group C patients $(30.5,32.4$, and 33 years; $P=0.148)$. Serum levels of CRP determined at the time of semen collection confirmed the absence of inflammation in all males and none of them reported any acute health problems.

\section{Sperm parameters}

There was no significant difference in the volume of ejaculates between groups A, B and C (Table 1). Groups $\mathrm{A}$ and $\mathrm{B}$ had similar sperm concentration, total sperm count and percentage normal morphology, however sperm motility was significantly higher in group A than group B. Group C patients has significantly lower sperm count, percentage motility and normal morphology than groups A or B (Table 1). 
Table1. Spermiogram parameters (mean \pm SD) in healthy volunteers $(A)$ and men of infertile couples (B and C). Mann-Whitney U test was utilized to compare groups.

\begin{tabular}{|l|c|c|c|c|c|c|}
\hline & $\begin{array}{c}\text { group A } \\
(\mathrm{n}=36) \\
\text { mean } \pm \text { SD }\end{array}$ & $\begin{array}{c}\text { group B } \\
(\mathrm{n}=67) \\
\text { mean } \pm \mathrm{SD}\end{array}$ & $\begin{array}{c}\text { group C } \\
(\mathrm{n}=98) \\
\text { mean } \pm \mathrm{SD}\end{array}$ & $\begin{array}{c}\text { A: B } \\
\mathrm{p}\end{array}$ & $\begin{array}{c}\text { A: C } \\
\mathrm{p}\end{array}$ & $\begin{array}{c}\mathrm{B} \text { C } \\
\mathrm{p}\end{array}$ \\
\hline $\begin{array}{l}\text { ejaculate volume } \\
(\mathrm{m})\end{array}$ & $3.1 \pm 1.3$ & $3.3 \pm 1.2$ & $3.0 \pm 1.5$ & 0.352 & 0.912 & 0.213 \\
\hline $\begin{array}{l}\text { sperm concentration } \\
\left(10^{6} / \mathrm{ml}\right)\end{array}$ & $69.6 \pm 35.6$ & $66.7 \pm 28.4$ & $39.8 \pm 27.6$ & 0.942 & 0.00003 & 0.00004 \\
\hline $\begin{array}{l}\text { total sperm count } \\
\left(\mathrm{x} 10^{6}\right)\end{array}$ & $198 \pm 96$ & $213 \pm 122$ & $115 \pm 95$ & 0.857 & 0.00004 & 0.00002 \\
\hline $\begin{array}{l}\text { motility } \\
(\%)\end{array}$ & $50 \pm 8$ & $53 \pm 5$ & $38 \pm 13$ & 0.030 & 0.00002 & 0.00001 \\
\hline $\begin{array}{l}\text { normal morphology } \\
(\%)\end{array}$ & $35.9 \pm 9.4$ & $38.0 \pm 6.8$ & $21.5 \pm 8.5$ & 0.230 & 0.00001 & 0.00001 \\
\hline
\end{tabular}

Table 2. ROS production in medians and $90^{\text {th }}$ centiles of $\log$ ROS and corresponding ROS production in RLU/min.

\begin{tabular}{|c|c|c|c|c|c|c|}
\hline $\begin{array}{l}\text { ROS } \\
\text { production }\end{array}$ & $\begin{array}{l}\text { group A } \\
(\mathrm{n}=36)\end{array}$ & $\begin{array}{l}\text { subgroup B1 } \\
(\mathrm{n}=59)\end{array}$ & $\begin{array}{c}\text { subgroup } \mathrm{C} 1 \\
(\mathrm{n}=84)\end{array}$ & $\begin{array}{c}\mathrm{A}: \mathrm{B} 1 \\
\mathrm{p}\end{array}$ & $\begin{array}{c}\mathrm{A}: \mathrm{C} 1 \\
\mathrm{p}\end{array}$ & $\begin{array}{c}\text { B1 : } \mathrm{C} 1 \\
\mathrm{p}\end{array}$ \\
\hline median log ROS & 3.015 & 2.698 & 3.317 & 0.178 & 0.439 & 0.026 \\
\hline approx. in RLU/min & 1000 & 500 & 2100 & & & \\
\hline $90^{\text {th }}$ centile $\log$ ROS & 4.367 & 4.357 & 4.731 & & & \\
\hline \multirow[t]{2}{*}{ approx. in RLU/min } & 23200 & 22800 & 53800 & & & \\
\hline & & $\begin{array}{c}\text { subgroup B2 } \\
(\mathrm{n}=8)\end{array}$ & $\begin{array}{c}\text { subgroup C2 } \\
(\mathrm{n}=10)\end{array}$ & $\begin{array}{c}\mathrm{A}: \mathrm{B} 2 \\
\mathrm{p}\end{array}$ & $\begin{array}{c}\mathrm{A}: \mathrm{C} 2 \\
\mathrm{p}\end{array}$ & $\begin{array}{c}\mathrm{B} 2: \mathrm{C} 2 \\
\mathrm{p}\end{array}$ \\
\hline median log ROS & 3.015 & 3.737 & 5.185 & 0.394 & 0.00004 & 0.008 \\
\hline approx. in RLU/min & 1000 & 5600 & 153000 & & & \\
\hline $90^{\text {th }}$ centile $\log$ ROS & 4.367 & 4.904 & 5.866 & & & \\
\hline \multirow[t]{2}{*}{ approx. in RLU/min } & 23200 & 80200 & 735000 & & & \\
\hline & & $\begin{array}{c}B 1+B 2 \\
(n=67)\end{array}$ & $\begin{array}{l}\mathrm{C} 1+\mathrm{C} 2 \\
(\mathrm{n}=94)\end{array}$ & $\begin{array}{c}\mathrm{B} 1: \mathrm{B} 2 \\
\mathrm{p}\end{array}$ & $\begin{array}{c}\mathrm{C} 1: \mathrm{C} 2 \\
\mathrm{p}\end{array}$ & $\begin{array}{c}\mathrm{B}: \mathrm{C} \\
\mathrm{p}\end{array}$ \\
\hline median log ROS & & 2.782 & 3.424 & 0.158 & 0.0002 & 0.0004 \\
\hline approx. in RLU/min & & 605 & 2656 & & & \\
\hline $90^{\text {th }}$ centile $\log$ ROS & & 4.406 & 5.155 & & & \\
\hline approx. in RLU/min & & 25725 & 143326 & & & \\
\hline
\end{tabular}

\section{Endtz, test}

Seminal PMN concentration was lower than $0.5 \times 10^{6} /$ $\mathrm{ml}$ in all fertile volunteers. Only 4 males from group $\mathrm{C}$ had leukocytospermia as defined by WHO and were excluded from statistical analysis. All non-leukocytospermic subjects were further subdivided on the basis of seminal PMN concentration into two subgroups: $(1)<0.5 \times 10^{6} /$ $\mathrm{ml}$ and (2) $0.5 \times 10^{6} / \mathrm{ml}$ to $1 \times 10^{6} \mathrm{PMN} / \mathrm{ml}$.

Among group B patients, 59 were in subgroup 1 (B1) and 8 in subgroup 2 (B2). Among the $\mathrm{C}$ group patients, 84 men had a PMN concentration $<0.5 \times 10^{6} / \mathrm{ml}(\mathrm{C} 1)$ and 10 men had PMN concentration $>0.5 \times 10^{6} / \mathrm{ml}(\mathrm{C} 2)$.

\section{ROS production}

The results of the luminol chemiluminescence assay varied greatly from 100 to $115000 \mathrm{RLU} / \mathrm{min}$ generated by $20 \times 10^{6}$ spermatozoa in our healthy fertile volunteers, from 100 to $354000 \mathrm{RLU} / \mathrm{min}$ in normospermic study subjects and from 100 up to 16 million in men with sperm abnormalities. Due to this extremely large range of values, logarithms of ROS production in RLU/min were used for non-parametric statistical evaluation (Table 2). When the three groups (A, B, C) were compared, group C patients had significantly higher median log ROS level than group $\mathrm{A}$ or $\mathrm{B}(\mathrm{P}=0.0002, \mathrm{P}=0.0004$, respectively $)$, whereas groups $\mathrm{A}$ and $\mathrm{B}$ had similar median $\log$ ROS level ( $\mathrm{P}=$ 0.158). Within group comparison based on PMN count 
cut-off of $0.5 \times 10^{6} / \mathrm{ml}$ revealed that $\mathrm{C} 2$ subgroup had significantly higher median log ROS level than subgroup $\mathrm{C} 1(\mathrm{P}=0.0002)$. However, although the median ROS production in the normospermic subgroup B2 $(n=8)$ was over ten times higher than subgroup B1, the difference did not reach statistical significance. Between subgroup comparison revealed that B1 subgroup had significantly lower median log ROS level than $\mathrm{C} 1$ subgroup $(\mathrm{P}=0.026)$. Similarly, B2 subgroup had significantly lower median $\log$ ROS level than $\mathrm{C} 2$ subgroup $(\mathrm{P}=0.008)$. There were no significant differences in median ROS levels between group A and subgroups B1 or subgroup C1.

\section{DISCUSSION}

In this study we compared healthy fertile volunteers with the male partners of couples presenting with infertility, to evaluate semen leukocyte count and ROS level. Patients with normal spermiogram (group B) had significantly lower ROS level than patients with abnormal spermiogram (group C). All fertile volunteers had PMN count $<0.5 \times 10^{6} / \mathrm{ml}$. Within group B and group C, the ROS level was lower in those with PMN count $<0.5 \times 10^{6} / \mathrm{ml} \mathrm{com-}$ pared to those with $\mathrm{PMN}$ count $0.5 \times 10^{6} / \mathrm{ml}$ to $1 \times 10^{6} / \mathrm{ml}$. However the difference reached statistical significance only in group $\mathrm{C}$.

Inspite of the known negative effects of oxidative stress on male fertility and the reported beneficial clinical effects of anti-inflammatory and antioxidant treatments in cases of male infertility ${ }^{16-19}$, the quantitative aspects of free radical production in human semen are still poorly understood. The reasons for this are several. First, the direct measurement of ROS production is almost impossible due to their extremely short half-life. Secondly, modern methods such as Electron Paramagnetic Resonance (EPR) or Electron Spin Resonance (ESR) spectroscopy ${ }^{20}$ require sophisticated instrumentation, are time consuming and hence not suitable for clinical practice. Thirdly, though the relatively simple indirect methods based on ROStriggered luminol or lucigenin chemiluminescence have been used for measurement in human sperm ${ }^{15,21,22}$ for about 20 years, the absolute data from different settings, referred to alternatively as photons, counts or RLU per minute, are difficult to compare because counting efficiency is unique for a given luminometer. Finally, measurement of ROS in washed sperm suspension is performed in an artificial environment with depleted antioxidants. A promising approach to circumvent this problem may be to assess the actual oxidant/antioxidant balance by measurement of ROS production in neat semen ${ }^{23}$.

Excessive ROS in the male genital tract may be generated by two cell types: immature and/or pathological spermatozoa and activated PMN and/or macrophages. Opinions continue to differ about the relative contribution of individual radicals from these two sources to the total ROS production in semen, although logically, the immature or pathologic spermatozoa in males with sperm abnormalities would be expected to make a greater con- tribution than in normospermic males ${ }^{22}$. This possibility was actually reflected in our finding of significantly higher ROS levels in subgroup $\mathrm{C} 1$ compared to $\mathrm{B} 1(\mathrm{P}=0.026)$. The highest increase in ROS production was found in 10 males from subgroup $\mathrm{C} 2$ with $\mathrm{PMN}$ concentrations between $0.5 \times 10^{6} / \mathrm{ml}$ and $1.0 \times 10^{6} / \mathrm{ml}(\mathrm{P}=0.00004)$ compared to fertile volunteers. Our findings therefore provide additional evidence of the importance of leukocyte infiltration in excessive ROS production in human semen.

Spermatozoa produce mainly superoxide which reacts with nitric oxide to form peroxynitrite, a putative mediator of oxidative cellular injury. But activated PMN and macrophages produce a more persistent molecule, $\mathrm{H}_{2} \mathrm{O}_{2}$, which can penetrate plasma membranes ${ }^{13}$, and which may easily form a very strong oxidant hydroxyl-radical $\left(\mathrm{OH}^{-}\right)$ in Fenton reaction ${ }^{3}$. In 1999, Ochsendorf ${ }^{8}$ suggested that only very high leukocyte contamination of semen (over $2.0 \times 10^{6} / \mathrm{ml}$ ) produces ROS which cannot be efficiently scavenged by the antioxidant capacity of seminal plasma. In contrast to this report, we found no semen with more than $2.0 \times 10^{6} \mathrm{PMN} / \mathrm{ml}$ and yet we observed some extremely high levels of ROS production. Recently, several authors have suggested that even much lower concentrations of PMN can produce detrimental amounts of $\mathrm{ROS}^{24}$. Sharma et $\mathrm{al}^{25}$ observed that any presence of PMN between 0 and $1.0 \times 10^{6} / \mathrm{ml}$ was associated with oxidative stress and were unable to determine a "safe" minimal leukocyte count. Henkel et $\mathrm{al}^{26}$ analyzed ROS production in 63 non-leukocytospermic patients and claimed that the "intrinsic" ROS production (percentage of spermatozoa producing ROS) calculated using dihydroethidine as a probe in a microslide smear of sperm suspension in PBS is significantly higher in patients with more than as little as $0.1 \times 10^{6}$ leukocytes per $\mathrm{ml}$ of ejaculate.

Using a combination of EPR, chemiluminiscence and nitroblue tetrazolium dye reduction, Armstrong et $\mathrm{al}^{20}$ also found that ROS-producing activity of spermatozoa may be different and significantly lower than that of leukocytes. The mechanism of ROS generation in human sperm depends upon a novel NADPH-oxidase (NOX5) resembling the multicomponent NADPH-oxidase of leukocytes, but having a significantly lower activity. The pro-oxidative potential of leukocytes in semen may be further enhanced by bacterial products and cytokines.

Kovalski et a $\mathrm{l}^{19}$ warned that $\mathrm{H}_{2} \mathrm{O}_{2}$ and $\mathrm{OH}$ produced by concentrations of PMN in semen as low as $0.6 \times 10^{6} /$ $\mathrm{ml}$ can be hazardous for spermatozoa, as seminal plasma may not always provide sufficient antioxidant protection. Recent measurements using flow-cytometry and monoclonal antibodies may be helpful in the identification of WBC subpopulations in human semen ${ }^{27}$. Based on their results the authors suggested lowering the WHO threshold value for leukocytospermia to $0.2 \times 10^{6} \mathrm{PMN} / \mathrm{ml}$. Another study confirmed that seminal PMN below $1.0 \times 10^{6}$ may be associated with increased ROS generation ${ }^{24}$.

The conflict of opinion concerning the correct threshold for detrimental leukocyte infiltration in human semen may be explained by the fact that within normal semen there may exist sperm subpopulations with different bio- 
chemical control mechanisms enabling them to defend themselves against leukocyte-derived $\operatorname{ROS}^{28}$. These authors also stress the need for a more detailed evaluation of leukocyte contamination of seminal fluid in order to better understand their role in oxidative stress.

\section{CONCLUSIONS}

In conclusion, our finding of increased ROS production in men from infertile couples with leukocyte contamination exceeding the level of $0.5 \times 10^{6} \mathrm{PMN} / \mathrm{ml}$ in ejaculate are consistent with some of these reports ${ }^{19,24}$. In the light of the acknowledged negative effects of oxidative stress on fertility potential of spermatozoa especially in assisted reproduction procedures we also suggest that the current WHO Guidelines threshold for normospermia of $1.0 \times 10^{6}$ $\mathrm{PMN} / \mathrm{ml}$ is too high and should be re-evaluated.

\section{ACKNOWLEDGEMENT}

The authors thank Dr. Krskova from the Computing centre of the Palacky University for statistical analysis.

The study was supported by the Grant project of the Internal Grant Agency of the Czech Ministry of Health under the reg. No A1 8621-5.

\section{REFERENCES}

1. Shekarriz M, Sharma RK, Thomas AJ Jr, Agarwal A. Positive myeloperoxidase staining (Endtz test) as an indicator of excessive reactive oxygen species formation in semen. J Assist Reprod Genet $1995 ; 12: 70-4$.

2. WHO laboratory manual for the examination of human semen and sperm-cervical mucus interaction. Cambridge, University Press, Cambridge, UK, 1999.

3. Wang A, Fanning L, Anderson DJ, Loughlin KR. Generation of reactive oxygen species by leukocytes and sperm following exposure to urogenital tract infection. Arch Androl 1997; 39:11-7.

4. Walrand S, Valeix S, Rodriguez C, Ligot P, Chassagne J, Vasson MP. Flow cytometry study of polymorphonuclear neutrophil oxidative burst: a comparison of three fluorescent probes. Clin Chim Acta 2003; 331:103-10.

5. de Lamirande E, Jiang H, Zini A, Kodama H, Gagnon C: Reactive oxygen species and sperm physiology. Reviews of Reproduction 1997; 2:48-54

6. Agarwal A, Gupta S, Sharma R.Oxidative stress and its implications in male infertility - a clinician's perspective. Reprod Biomed Online 2005; 11:641-50.

7. Donnelly ET, Steele EK, McClure N, Lewis SE.Assessment of DNA integrity and morphology of ejaculated spermatozoa from fertile and infertile men before and after cryopreservation. Hum Reprod 2001; 116:1191-9.

8. Ochsendorf FR. Infections in the male genital tract and reactive oxygen species. Human Reprod Update 1999; 5:399-420.

9. Said TM, Aziz N, Sharma RK, Lewis-Jones I, Thomas AJ Jr, Agarwal A. Novel association between sperm deformity index and oxidative stress-induced DNA damage in infertile male patients. Asian J Androl 2005; 7:121-6.

10. O WS, Chen H, Chow PH. Male genital tract antioxidant enzymes their ability to preserve sperm DNA integrity. Mol Cell Endocrinol 2006; 250:80-3.

11. Aitken RJ, Baker MA. Oxidative stress, sperm survival and fertility control. Mol Cell Endocrinol 2006; 250:66-9.

12. Maruyama DK, Hale RW, Rogers BJ. Effects of white blood cells on the in vitro penetration of zona-free hamster eggs by human spermatozoa. J Androl 1985; 64:127-35.

13. Moskovtsev SI, Willis J, White J, Mullen JBM. Leukocytospermia: relationship to sperm deoxyribonucleic acid integrity in patients evaluated for male factor infertility. Fertil Steril 2007; 88:737-40

14. Sharma RK, Said T, Agarwal A. Sperm DNA damage and its clinical relevance in assessing reproductive outcome. Asian J Androl 2004; 6: 139-48.

15. Novotny J, Oborna I, Brezinova J, Svobodova M, Hrbac J, Fingerova $\mathrm{H}$. The occurrence of reactive oxygen species in semen of males from infertile couples. Biomed papers 2003; 147:173-6.

16. Sheweita SA, Abdulkarim MT, Al-Sawaf H. Mechanisms of male infertility: role of antioxidants. Curr Drug Metab 2005; 6:495-501.

17. Oborna I, Fingerova H, Hajduch M, Svobodova M, Brezinova J, Vostalova J., Novotny J. Lycopene therapy in male infertility (in Czech). Cs Gynek 2007; 71:326-9.

18. Agarwal A, Prabakaran SA, Allamaneni S. What an adrologist should know about free radicals and why. Urology 2006; 67:2-8.

19. Kovalski NN, de Lamirande E, Gagnon C. Reactive oxygen species generated by human neutrophils inhibit sperm motility: protective effect of seminal plasma and scavengers. Fertil Steril 1992; 4:80916.

20. Armstrong JS, Bivalacqua TJ, Chamulitrat W, Sikka S, Hellstrom WJ. A comparison of the NADPH oxidase in human sperm and white blood cells. Int J Androl 2002; 25:223-9.

21. Aitken RJ, Buckingham DW, West KM. Reactive oxygen species and human spermatozoa: analysis of the cellular mechanisms involved in luminol- and lucigenin- dependent chemiluminescence. J Cell Physiol 1992; 151:466-77.

22. Gil-Guzman E, Ollero M, Lopez MC, Sharma RK, Alvarez JG, Thomas AJ Jr, Agarwal A. Differential production of reactive oxygen species by subsets of human spermatozoa at different stages of maturation. Hum Reprod 2001; 16:1922-30.

23. Allamaneni SS, Agarwal A, Nallella KP, Sharma RK, Thomas AJ Jr, Sikka SC. Characterization of oxidative stress status by evaluation of reactive oxygen species levels in whole semen and isolated spermatozoa. Fertil Steril 2005; 83:800-3.

24. Athayde KS, Cocuzza M, Agarwal A, Krajcir N, Lucon AM, Srougi $M$, et al. Development of normal reference values for seminal reactive oxygen species and their correlation with leucocytes and semen parameters in fertile population. J Androl 2007; 28, 613-20 (Epub).

25. Sharma RK, Pasqualotto FF, Nelson DR, Thomas AJ Jr, Agarwal A. Relationship between seminal white blood cell counts and oxidative stress in men treated at an infertility clinic. J Androl 2001; 22:575-83.

26. Henkel R, Kierspel E, Stalf T, Mehnert C, Menkveld R, Tinneberg HR, et al. Effect of reactive oxygen species produced by spermatozoa and leukocytes on sperm functions in non-leukocytospermic patients. Fertil Steril. 2005; 83:635-42.

27. Ricci G, Presani G, Guaschino S, Simeone R, Perticarari S. Leukocyte detection in human semen using flow cytometry. Hum Reprod 2000; 15:1329-37.

28. Fraczek M, Sanocka D, Kurpisz M. Interaction between leucocytes and human spermatozoa influencing reactive oxygen intermediates release. Int J Androl 2004; 2:69-75. 
